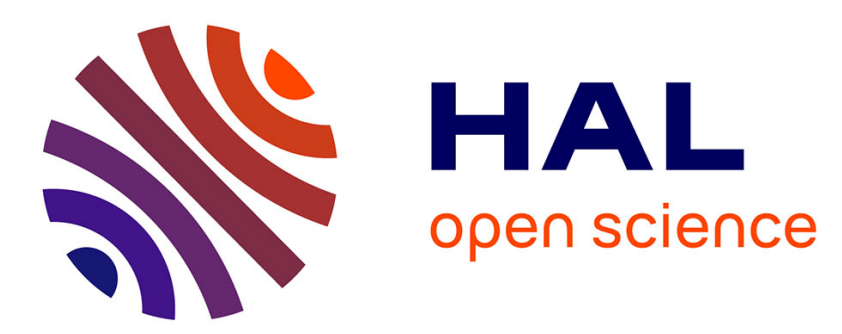

\title{
ADALINE approach for induction motor mechanical parameters identification
}

Hamid Sediki, Ali Bechouche, Djaffar Ould Abdeslam, Salah Haddad

\section{To cite this version:}

Hamid Sediki, Ali Bechouche, Djaffar Ould Abdeslam, Salah Haddad. ADALINE approach for induction motor mechanical parameters identification. Mathematics and Computers in Simulation, 2013, 90 (-), pp.86-97. 10.1016/j.matcom.2012.05.003 . hal-00985414

\section{HAL Id: hal-00985414 https://hal.science/hal-00985414}

Submitted on 29 Apr 2014

HAL is a multi-disciplinary open access archive for the deposit and dissemination of scientific research documents, whether they are published or not. The documents may come from teaching and research institutions in France or abroad, or from public or private research centers.
L'archive ouverte pluridisciplinaire HAL, est destinée au dépôt et à la diffusion de documents scientifiques de niveau recherche, publiés ou non, émanant des établissements d'enseignement et de recherche français ou étrangers, des laboratoires publics ou privés. 


\title{
ADALINE approach for induction motor mechanical parameters identification
}

\author{
Hamid Sediki ${ }^{\text {, }}$, Ali Bechouche ${ }^{\text {a }}$, Djaffar Ould Abdeslam ${ }^{\text {,*, }}$, Salah Haddad ${ }^{\text {a }}$ \\ ${ }^{a}$ Department of Electrical Engineering, Mouloud Mammeri University, BP 17 RP Tizi-Ouzou, Algeria \\ ${ }^{\mathrm{b}}$ MIPS Laboratory, University of Haute-Alsace, 4 rue des Frères Lumières, 68093 Mulhouse, France \\ * Corresponding author. Tel.: 33 (0)3 89336020 \\ E-mail address: djaffar.ould-abdeslam@uha.fr (D. Ould Abdeslam).
}

\begin{abstract}
Two new methods to identify the mechanical parameters in induction motor based field oriented drives are presented in this paper. The identified parameters are: the moment of inertia and the viscous damping coefficient. The proposed methods are based on the adaptive linear neuron (ADALINE) networks. The two parameters are derived and optimised during the online training process. During the identification phase, the motor torque is controlled by the well-known field oriented control strategy. This torque is subjected to variations in order to obtain mechanical speed transients. The two proposed methods are simple to implement compared to the previous techniques. They require only the stator current and mechanical speed measurements. Finally, the effectiveness of the two methods and the accuracy of the derived parameters are proven experimentally by two direct starting tests. The originality of this work is the building of a model representation that it is suitable for implementation with ADALINE networks. This leads to a simple implementation and ease of mechanical parameters identification.
\end{abstract}

Keywords: Adaptive linear neuron; Artificial neural networks; Field oriented control; Induction motor; Parameters identification

\section{Introduction}

To achieve high dynamic performance of induction motor (IM) speed control, knowledge of electric parameters is not sufficient. The mechanical parameters such as the moment of inertia and the viscous damping coefficient are needed and very important to design controllers and/or states observers. Therefore, it is essential to develop algorithms for IM mechanical parameters identification.

There are many proposed techniques that identify the motor parameters off-line. However, when these parameters are subject to variations, the motor control performances are deteriorated and the system becomes detuned. It is therefore suitable to track these changes online in order to ensure optimal controller tuning at any time. To identify the moment of inertia $J$, conventional methods can be used. They are based on direct and indirect techniques. The direct techniques consist of extracting the rotor and performing measurements which require other devices and not always adaptable for all electric motors. For indirect techniques, the slowdown method can be mentioned. This method requires that the turning system "shaft-end" should be accessible. Measurement is carried out by adding a known inertia wheel $J_{0}$ to the motor shaft. The slowdown curves both with and without the added inertia permit the deduction of the inertia moment $J$. The viscous damping coefficient $f$ can be estimated in steady state by measuring the power consumption at a given speed in no-load test. The use of conventional techniques in industrial environments for determining the mechanical parameters can be an arduous and complicated task. Moreover, these techniques are not able to track changes in the system parameters.

In recent years, several estimation strategies have been developed for mechanical parameters identification in field oriented controller drives. The advantage of the field oriented control (FOC) drives is the possibility to obtain the knowledge of the motor torque since the stator currents and the rotor flux are known [14]. In these conditions, many techniques are developed. The methods based on the least mean squares (LMS) algorithms and recursive least squares algorithms used for online identification [15] can be mentioned. The main limitation of these methods is due to its noise sensitivity. In several papers, observer's techniques have been attempted [3, 9]. In [3], an algorithm is proposed for identifying the moment of inertia by observing the position error signal generated by a speed observer which contains error information on the moment of inertia. A reduced-order extended Luenberger observer is also proposed to estimate the motor inertia value [10]. However, these methods require that some conditions such as observability must be checked and need a long computing-time at the implementation.

Recently, heuristic approaches for IM parameters identification are proposed and have provided efficient results. An off-line method based on the genetic algorithm is proposed to estimate mechanical and electrical parameters. Particle swarm optimisation algorithms are also attempted in order to identify the IM parameters. However, the most known and used heuristic method is that based on artificial neural networks (ANNs) [20]. For a few years, these techniques have been proposed and developed as an alternative to conventional methods for modern control challenges [8,11,13]. Latest papers demonstrate the ANN effectiveness in the 
state variable estimation and the IM parameters identification [2,5,20]. Among the ANN techniques, the most attractive for linear system identification is that based on single layer called adaptive linear neuron (ADALINE) networks. The main advantages of this technique are its simplicity and the ability to be trained online. In addition, the ADALINE weights can be interpreted physically $[2,12]$. It is thus very efficient for parameters identification of linear systems. In some areas such as adaptive signal processing [6] or current harmonics identification in power systems [12], the ADALINE has become a powerful tool.

This paper proposes and investigates the use of two new methods for online identification of IM mechanical parameters. These methods are based on the ADALINE and use LMS learning rule to perform the online training. The hardware implementation is very simple and does not require any additional costs other than that commonly used in FOC. The input/output vectors of the ADALINE are the stator current and the mechanical speed, respectively. These input/output vectors can be obtained by using simple sensor devices. The two methods provide the two parameters $J$ and $f$ online. It represents a main advantage when an online tuning controller is required.

The paper is organized as follows. Section 2 gives the IM model and the FOC principle used during the identification process. In section 3, the ADALINE basic concept, the learning process and the identification strategies are given. The obtained experimental results are presented in section 4 . Finally, section 5 is devoted to conclusions.

\begin{tabular}{|ll}
\hline Nomenclature & \\
$L_{s}$ & Stator cyclic inductance. \\
$R_{s}$ & Stator resistance. \\
$T_{r}$ & Rotor time constant. \\
$J$ & Moment of inertia. \\
$f$ & Viscous damping coefficient. \\
$T_{l}$ & Total load torque. \\
$T_{d}$ & Disturbance load torque. \\
$\Gamma_{s}$ & Coulomb friction. \\
$T_{e m}$ & Electromagnetic torque. \\
$\left.I_{r m d}, I_{r m q}{ }^{2}{ }^{2}\right)^{1 / 2}$ & Rotor magnetizing currents in $(d, q)$ frame. \\
$I_{r m}=\left(I_{r m d}+I_{r m q}\right)^{2}$ & Module of the rotor magnetizing current. \\
$p$ & Number of pole pairs. \\
$\omega_{s}$ & Synchronous pulsation. \\
$\Omega$ & Mechanical speed. \\
$\sigma$ & Leakage factor. \\
$s, r$ & Subscripts indicating stator and rotor. \\
$T_{e}$ & Sampling period.
\end{tabular}

\section{Induction motor mechanical model under field-oriented control}

The main objective of the FOC is, as in DC motors, to independently control the electromagnetic torque and the rotor flux. This is performed by using a $d-q$ rotating frame synchronously with the rotor flux space vector. As shown in Fig. 1, the $d$ axis is aligned with the rotor magnetizing current space vector, which yields $I_{r m q}=0$ and $I_{r m d}=I_{r m}$. The rotor magnetizing current $I_{r m}$ is generated by the $I_{s d}$ component. Under steady state conditions, $I_{s d}$ is equal to $I_{r m}$. The rotor flux angular speed $\omega_{s}$ is calculated by adding the rotor electric speed $(p . \Omega)$ to the motor slip pulsation $\omega_{r}$. The direct and inverse Park transformations require an input angle $\theta_{s}$ obtained by integrating the field pulsation $\omega_{s}$. The slip pulsation is expressed by the rotor time constant $T_{r}$, the quadratic stator current $I_{s q}$ and the rotor magnetizing current $I_{r m}$.

If suitable orientation of the stator current and the rotor flux is maintained, the rotor flux and the electromagnetic torque can be controlled independently [14]. The $I_{s d}$ current controls the rotor flux through the direct axis stator voltage $V_{s d}$ and the $I_{s q}$ current controls the electromagnetic torque $T_{e m}$ through the quadratic axis stator voltage $V_{s q}$. This is the key of indirect FOC.

With the FOC implementation, $I_{r m}, \omega_{s}$ and $T_{e m}$ can be estimated by

$$
\begin{aligned}
& \hat{I}_{r m}=\frac{a_{1}}{s+a_{1}} I_{s d} \\
& \hat{T}_{e m}=b_{1} \hat{I}_{r m d} I_{s q} \\
& \hat{\omega}_{s}=p \Omega+\hat{\omega}_{r}=p \Omega+a_{1} I_{s q} / \hat{I}_{r m_{-} r e f}
\end{aligned}
$$

with $a_{l}=1 / T_{r}$ and $b_{l}=p(1-\sigma) L_{s}$. 
The IM control scheme adopted for the mechanical parameters identification is shown in Fig. 1. Two proportional-integral (PI) regulators are used to control the electromagnetic torque $T_{e m}$ and the rotor magnetizing current $I_{r m d}$. In order to reconstitute the voltage vectors $V_{s d}$ and $V_{s q}$, to be applied to the IM, the decoupling terms $E_{d}$ and $E_{q}$ are added at the output of each regulator.

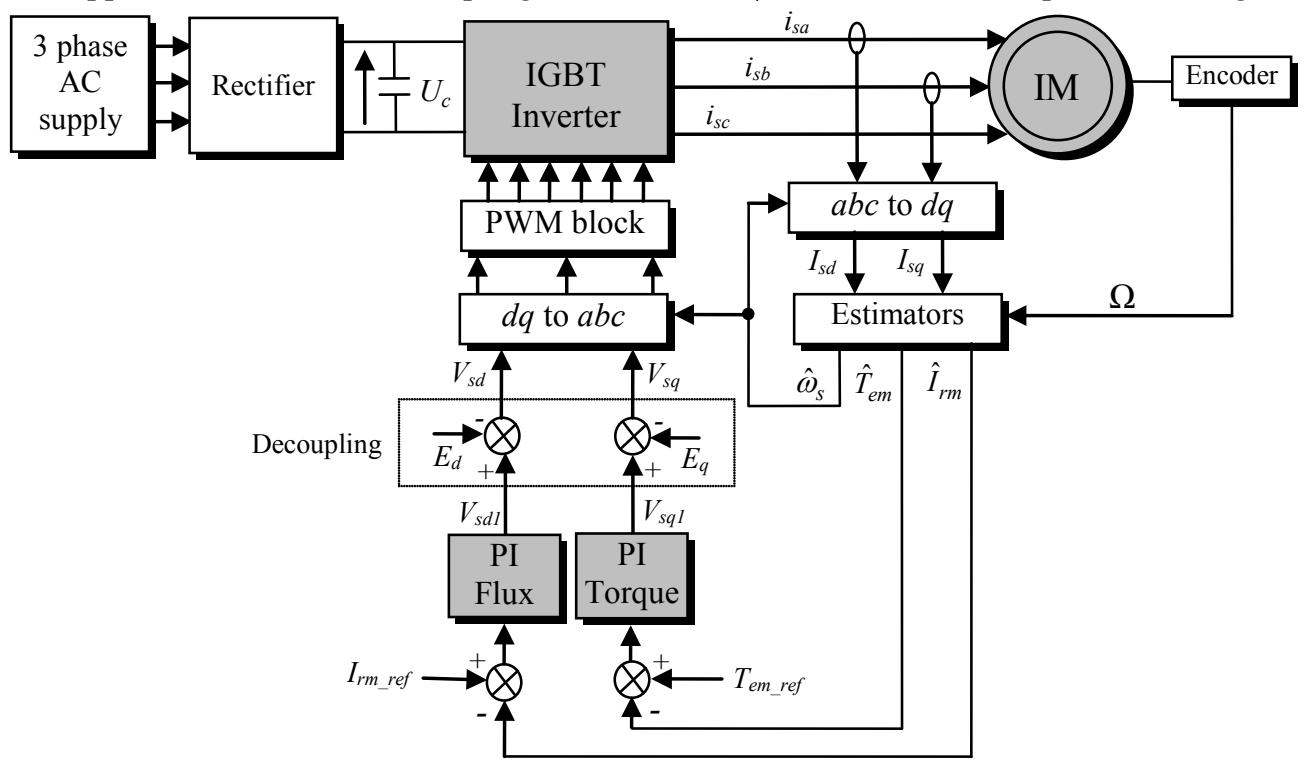

Fig. 1. IM control scheme used in the identification process.

The functional diagram of the mechanical system is shown in Fig. 2. This model is described by the following differential equation:

$$
d \Omega / d t=\left(T_{e m}-T_{l}\right) / J
$$

with:

$$
T_{l}=f \Omega+\operatorname{sign}(\Omega) \Gamma_{s}+T_{d}
$$

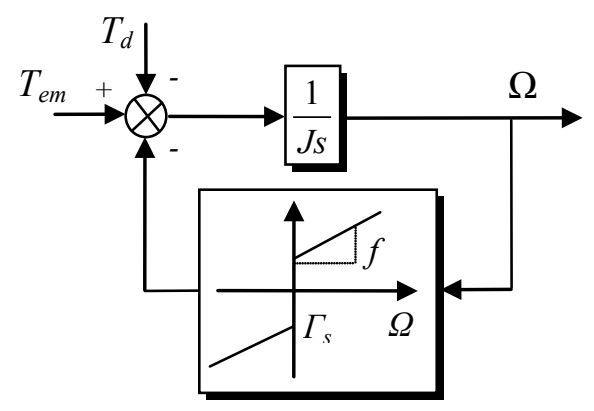

Fig. 2. Functional diagram of the mechanical system.

Under some assumptions like $T_{d}=0$ and $\Gamma_{s}=0$, the relationship between the rotor speed and the electromagnetic torque is given by the following transfer function:

$$
\frac{\Omega}{T_{e m}}=\frac{K}{\tau_{m} s+1}
$$

Where: $K=1 / f$ and $\tau_{m}=J / f$.

Though the IM dynamic behaviour is the same of the DC motor, the IM control performance is still significantly influenced by the system uncertainties including mechanical parameters. To improve the process control, the constants $K$ and $\tau_{m}$ must be known accurately. Thereafter, the mathematical model given by (6) will be used to determinate the parameters $K$ and $\tau_{m}$.

\section{ADALINE principles}

\subsection{ADALINE architecture}

The ADALINE neural network is well-known in the ANNs architecture. It has been applied successfully in many power applications, including current harmonics estimation [12], voltage and current components extraction of an unbalanced three-phase 
system [4], power quality disturbances detection [1], IM electric parameters identification [2,7], and feature of control [16]. As shown in Fig. 3, the ADALINE is equivalent to one neuron which is composed of an input vector $X_{k}$, a weights matrix $W_{k}$, and an activation function $f(v)$. The weights vector $W_{k}=\left[w_{0 k} w_{l k} \ldots w_{n k}\right]^{\mathrm{T}}$ corresponds to the whole neuron synaptic forces. The input vector $X_{k}=\left[1 x_{1 k} \ldots\right.$ $\left.x_{n k}\right]$ corresponds to the whole neuron input stimulus. The activation function $f(v)$ specifies the neuron behaviour.

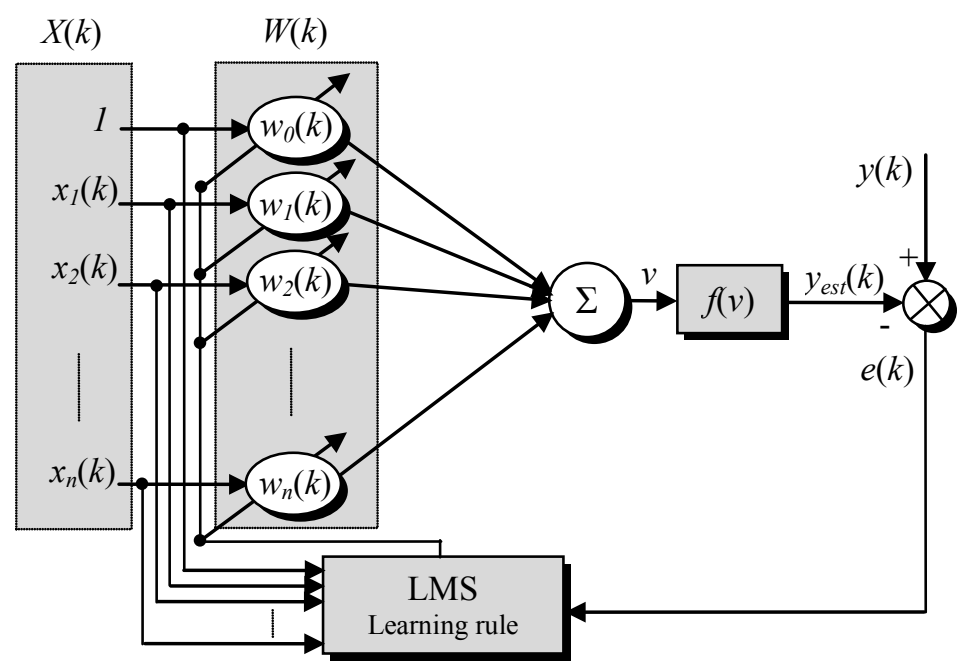

Fig. 3. ADALINE topology.

Various activation functions can be used in the ANN theory. However, the ADALINE uses the linear activation function $f(v)=v$. Consequently, the ADALINE output $y_{k}$ is given by: $y_{k}=X_{k} W_{k}$. When the ADALINE is excited, it produces the output $y_{k}$ which depends on the input vector. The weights vector $W_{k}$ is continuously modified during the network learning process with the purpose of approaching as close as possible the desired output $d_{k}$.

\subsection{ADALINE training}

In the ADALINE theory, the most known training process is that called $\mu$-LMS algorithm $[17,18,19]$. The weight vector is updated after the presentation of each input sample. The $\mu$-LMS algorithm is performed by using the steepest-descent gradient. It starts with an arbitrary initial value $W_{0}$ for the system's weight vector. The instantaneous gradient $\nabla_{k}$ upon the square of the instantaneous linear error is measured and the weight vector is altered in the direction corresponding to the measured negative gradient. The procedure is repeated, causing the mean square error to be successively reduced on average and causing the weight vector to approach a locally optimal value. The method of steepest descent can be described by the following expression:

$$
W_{k+1}=W_{k}+\mu\left(-\nabla_{k}\right)=W_{k}-\mu \frac{\partial e_{k}^{2}}{\partial W_{k}}
$$

where $\mu$ is a parameter that controls stability and convergence rate, and $\nabla_{k}$ is the instantaneous gradient value at $W=W_{k}$.

The ADALINE uses a supervised learning, so a desired output $d_{k}$ is provided with each input $X_{k}$ during the training phase. The error information is

$$
e_{k}=d_{k}-y_{k}=d_{k}-X_{k}^{T} W_{k}
$$

Performing the differentiation in (7) and replacing the linear error given by (8), we can write

and

$$
W_{k+1}=W_{k}-\mu \frac{\partial e_{k}^{2}}{\partial W_{k}}=W_{k}-2 \mu e_{k} \frac{\partial e_{k}}{\partial W_{k}}
$$

$$
W_{k+1}=W_{k}-2 e_{k} \mu \frac{\partial\left(d_{k}-X_{k}^{T} W_{k}\right)}{\partial W_{k}}
$$

$d_{k}$ and $X_{k}$ are independent of $W_{k}$, that leading to

$$
W_{k+1}=W_{k}-2 \mu e_{k} X_{k}^{T}
$$




\subsection{Learning rate}

The learning constant $\mu$ determines stability and convergence rate. For time independent input patterns, the weight vector mean and variance convergence is ensured for most practical purposes if

$$
0<\mu<1 / \text { trace }[R]
$$

Where trace $[R]=\Sigma$ (diagona1 elements of $R$ ) and $R$ is the input correlation matrix defined in ensemble average terms: $\mathrm{R}=E\left(X . X^{T}\right.$ ).

The learning rate $\mu$ is an important parameter. The choice of a small value for $\mu$ leads to a better network stability but the weights convergence can become very slow. Therefore, to accelerate the weights convergence and to refine the results, $\mu$ must be variable during the training process. Its value will be selected relatively high at the beginning, and will decrease significantly and have a small value at the end. The expression of $\mu$ can be selected by the following equation:

$$
\mu=\mu_{i}\left(\mu_{f} / \mu_{i}\right)^{\frac{t}{t_{\max }}}
$$

$\mu_{i}$ and $\mu_{f}$ are respectively the initial and the final values of the learning rate. $t_{\max }$ is the maximal training time.

\section{Identification strategies based on ADALINE}

The theoretical basis of this identification strategy is to find and to exploit the linear relationship existing between the weights and the mechanical parameters. If the weights adjustment gives the error between the actual and the estimated rotor speed to the minimum value, then the mechanical parameters are well known.

\subsection{Mechanical equation based method}

This method can be implemented with any form of torque command $T_{\text {em } r e f}$ and the resulted speed $\Omega$. To have a valid viscous damping coefficient in a wide speed range, it is preferable to apply alternate torques which lead to positive and negative speeds close to the nominal value.

Let us consider the mechanical equation (6) written in the recursive form

$$
\Omega(k)=B_{0} \Omega(k-1)+A_{0} T_{e m}(k-1)
$$

The coefficients $B_{0}$ and $A_{0}$ are equivalent to the ADALINE weights, $w_{1}$ and $w_{2}$ respectively, as represented in Fig. 4 . They are given by the following expressions:

$$
\left\{\begin{array}{l}
B_{0}=w_{1}=\exp \left(-T_{e} / \tau_{m}\right) \\
A_{0}=w_{2}=K\left(1-\exp \left(-T_{e} / \tau_{m}\right)\right)
\end{array}\right.
$$

Once the optimal weights $w_{l}$ and $w_{2}$ are correctly known during the training process, they can be used to calculate the parameters $f$ and $J$ by inversion of (15). Their expressions will be as follows:

$$
\left\{\begin{array}{l}
f=1 / K=\frac{1-w_{1}}{w_{2}} \\
J=\tau_{m} f=-f T_{e} / \ln \left(w_{1}\right)
\end{array}\right.
$$

The implementation block diagram of this method is shown in Fig. 4.

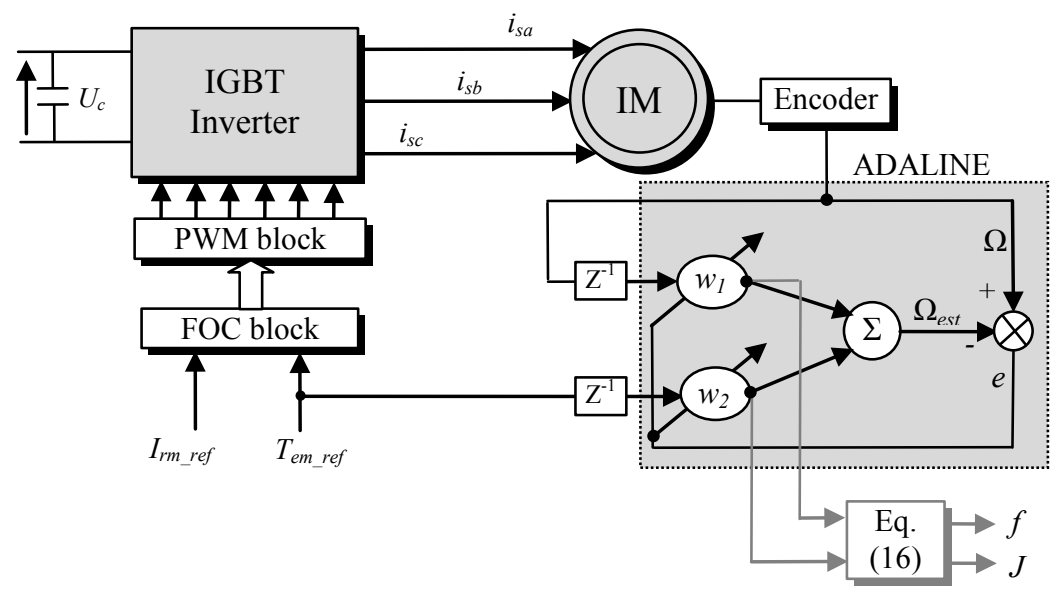

Fig. 4. Overall structure of ADALINE identifier for mechanical equation based method. 


\subsection{Harmonic speed response based method}

This method can be applied only if the imposed torque command $T_{\text {em_ref }}$ has a sinusoidal form. Theoretically, with this form of torque, the motor speed response would be also sinusoidal. The use of an ADALINE with two sinusoidal terms (sin $\omega t$ and cos $\omega t$ ) as inputs is suggested (Fig. 5). The ADALINE weights $w_{1}$ and $w_{2}$ will be adjusted during the training process to approach the measured mechanical speed. Once the weights converge towards fixed and optimal values, it is easy to derive the required mechanical parameters $f$ and $J$.

Let us give the mathematical formulation of this method. If the reference torque is defined as

$$
T_{\text {em_ref }}=T_{\text {em } \max } \sin \omega t
$$

and if the IM mechanical model is accurately given by (6), then, in steady state operating conditions the obtained speed response will be written as follows:

$$
\Omega(t)=\Omega_{\max } \sin (\omega t+\phi)
$$

The constants $\Omega_{\max }$ and $\phi$ are given by

$$
\left\{\begin{array}{l}
\Omega_{\max }=\sqrt{\frac{K^{2} T_{e m \text { max }}^{2}}{\tau_{m}^{2} \omega^{2}+1}} \\
\phi=-\arctan \tau_{m} \omega
\end{array}\right.
$$

The speed response given by (18) can be subdivided into two terms in the following way:

$$
\begin{aligned}
\Omega(t) & =\Omega_{\max }[\cos \phi \sin \omega t+\sin \phi \cos \omega t] \\
& =A_{1} \sin \omega t+B_{1} \cos \omega t
\end{aligned}
$$

Where: $\quad\left\{\begin{array}{l}A_{1}=\Omega_{\text {max }} \cos \phi \\ B_{1}=\Omega_{\text {max }} \sin \phi\end{array}\right.$

The two terms sin $ø t$ and $\cos \omega t$ will be considered as ADALINE inputs. As shown in Fig. 5, the constant terms $A_{1}$ and $B_{1}$ coincide with ADALINE weights $w_{1}$ and $w_{2}$ respectively. Once the weights are known, it is easy to reconstitute the mechanical parameters in the following way:

$$
\left\{\begin{array}{l}
\tan \phi=B_{1} / A_{1}=w_{2} / w_{1} \\
\Omega_{\text {max }}=\sqrt{A_{1}^{2}+B_{1}^{2}}=\sqrt{w_{1}^{2}+w_{2}^{2}}
\end{array}\right.
$$

Combining the relationships (19) with those given by (21) permits to obtain

$$
\left\{\begin{array}{l}
w_{1}^{2}+w_{2}^{2}=\frac{K^{2} T_{e m \max }^{2}}{\tau_{m}^{2} \omega^{2}+1} \\
w_{2} / w_{1}=-\tau_{m} \omega
\end{array}\right.
$$

Finally, solving the system (22) permits to derive the mechanical parameters

$$
\left\{\begin{array}{l}
f=\frac{1}{K}=\frac{w_{1} T_{e m \max }}{w_{2} \sqrt{w_{1}^{2}+w_{2}^{2}}} \\
J=\tau_{m} f=-f \frac{w_{2}}{w_{1} \omega}
\end{array}\right.
$$

The implementation principle diagram of this method is explained in Fig. 5. 


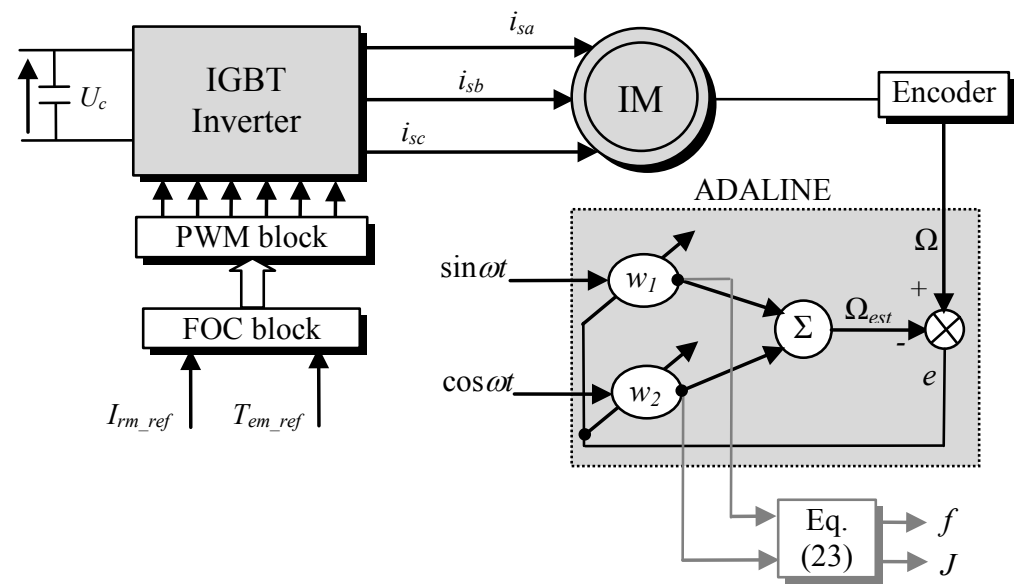

Fig. 5. Overall structure of ADALINE identifier for harmonic speed response based method.

\section{Experimental results}

The identified system is a squirrel cage IM. The electric parameters $R_{s}, L_{s}, \sigma$ and $T_{r}$ have been successfully identified by using ADALINE strategies [2]. The IM characteristics are given in Table 1. The IM is supplied by a voltage-source IGBT inverter. The FOC strategy, the Pulse Width Modulation (PWM) signals generation and the signals conditioning are carried out numerically via a dSPACE board based on a TMS320C31 floating point DSP. The control and the identification algorithms are implemented in MATLAB-Simulink using Runge-Kutta resolution method. The real-time interface is used to build real-time code (C language) and execute it on dSPACE hardware. The mechanical speed is measured by an incremental encoder with a global resolution of $2.10^{4}$ point/round. The stator phase currents are measured by Hall Effect transducers. All the signals can be visualized and recorded on a computer via the ControlDesk visualization software. A view of the test bench is given in Fig. 6.

Table 1

Induction motor characteristics

\begin{tabular}{ll}
\hline Rated power $(\mathrm{kW})$ & $P_{n}=3$ \\
Rated supply voltage $\Delta / \mathrm{Y}(\mathrm{V})$ & $U_{s n}=220 / 380$ \\
Stator rated current $\Delta / \mathrm{Y}(\mathrm{A})$ & $I_{s n}=11 / 6.3$ \\
Rated speed $(\mathrm{rpm})$ & $N_{n}=1415$ \\
Number of pole-pairs & $p=2$ \\
Stator resistance $(\Omega)$ & $R_{s}=1.5$ \\
Stator cyclic inductance $(\mathrm{H})$ & $L_{s}=0.22$ \\
Leakage factor & $\sigma=0.0872$ \\
Rotor time constant $(\mathrm{s})$ & $T_{r}=0.099$ \\
\hline
\end{tabular}

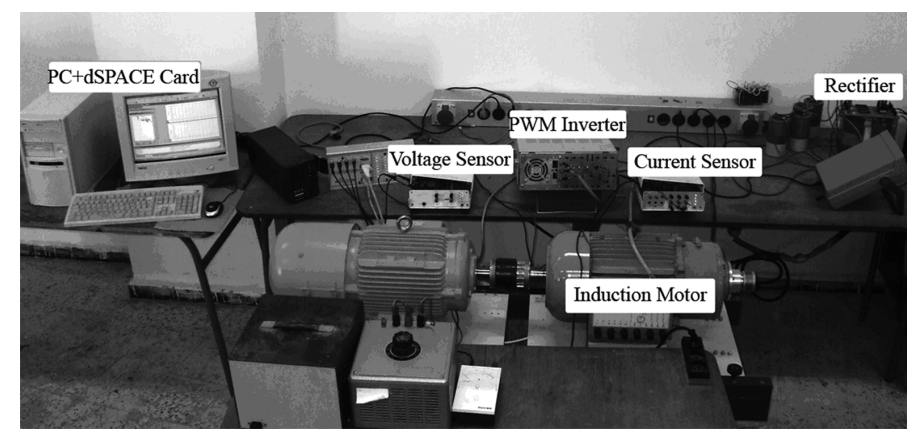

Fig. 6. View of the test bench.

To obtain an accurate identification and a fast convergence of the used methods, some adjustments were carried out. The identification signals must contain the least amount of noise possible. Therefore, the mechanical speed signal, delivered by the incremental encoder, is filtered by a first order low-pass filter. The actual torque is substituted by the torque reference. This approximation is justified since the identification signals are relatively slow compared to the torque regulator response time. The identification was carried out with a sinusoidal torque reference. Its magnitude is $2.25 \mathrm{Nm}$ and the pulsation is set to $0.6 \mathrm{rad} / \mathrm{s}$. The 
motor rotation speed reaches $90 \mathrm{rad} / \mathrm{s}$. The maximal and minimal values of the learning rates, ensuring an optimal speed convergence, are experimentally adjusted respectively to $\eta_{\max }=4.10^{-5}$ and $\eta_{\min }=10^{-7}$. The sampling period used in the identification process is $T_{e}=0.5 \mathrm{~ms}$.

Fig. 7 shows the identification signals waveform; the torque reference and the measured speed. It can be noted that the resulted speed waveform is not completely sinusoidal, especially with the zero crossing. That is explained by the viscous damping coefficient $f$ which is not constant but depends on the mechanical speed. Indeed, $f$ is very high at low speeds and becomes small when the IM operates at high speeds.

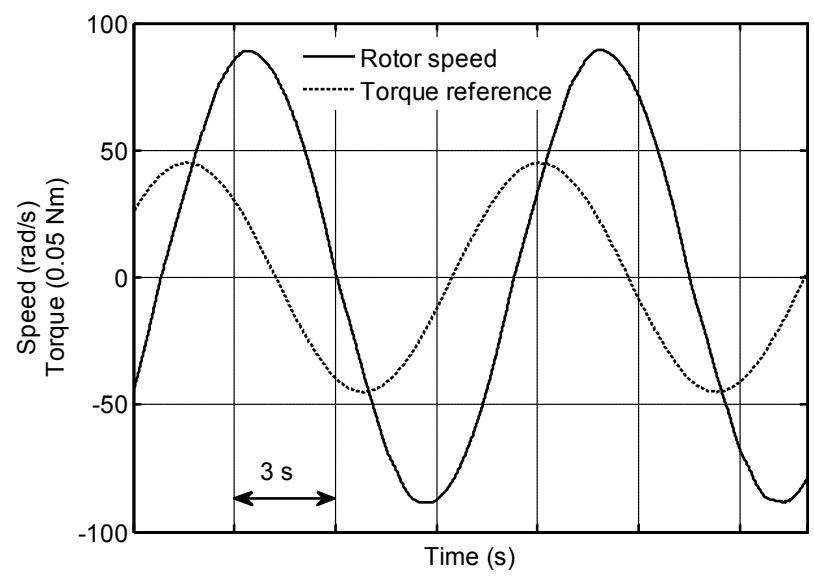

Fig. 7. Identification signals: torque reference and rotor speed.

\subsection{Mechanical speed equation based method}

Fig. 8(a) shows the ADALINE weights evolution $w_{1}$ and $w_{2}$. After the transient state, the weights are stabilized at the values: $w_{1}=0.9998$ and $w_{2}=0.0133$. As shown in Fig. $8(\mathrm{~b})$, the residual error is very low, which is what justifies the good performance of the ADALINE network. Fig. 9 shows the identified parameters. In the steady state, the identified values are: $J=0.037 \mathrm{~kg} . \mathrm{m}^{2}$ (Fig. 9 (b)) and $f=0.012$ N.m.s/rad (Fig. 9(a)). The fluctuating value of $f$ is explained by the fact that the viscous dumping coefficient is not constant. The obtained value of $f$ is only an average in this speed range.

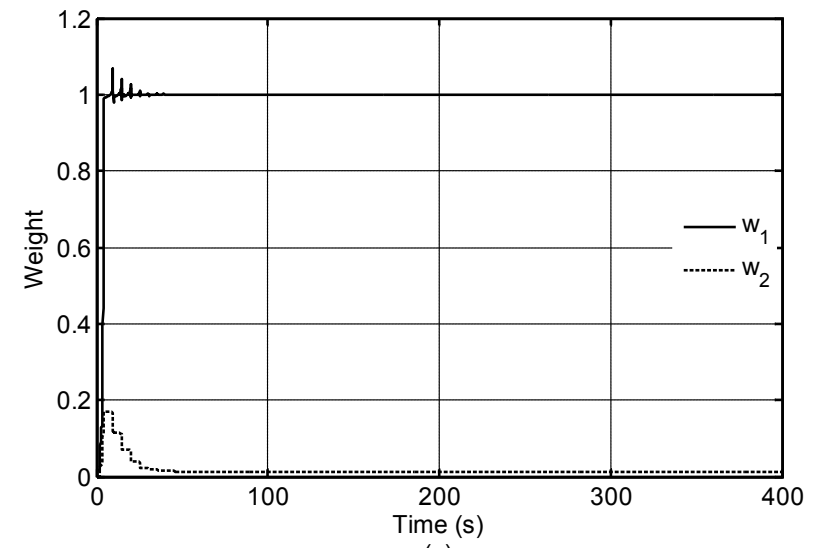

(a)

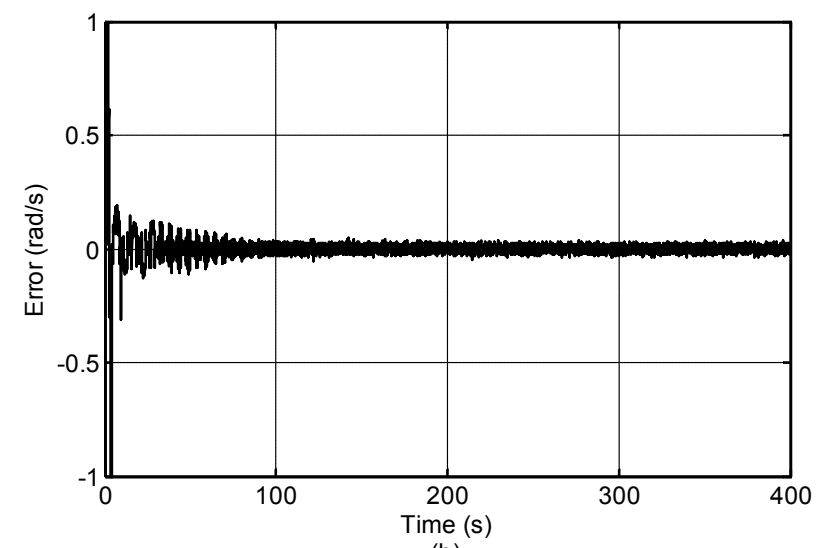

(b)

Fig. 8. Evolution of the weights (a) and prediction error (b). 


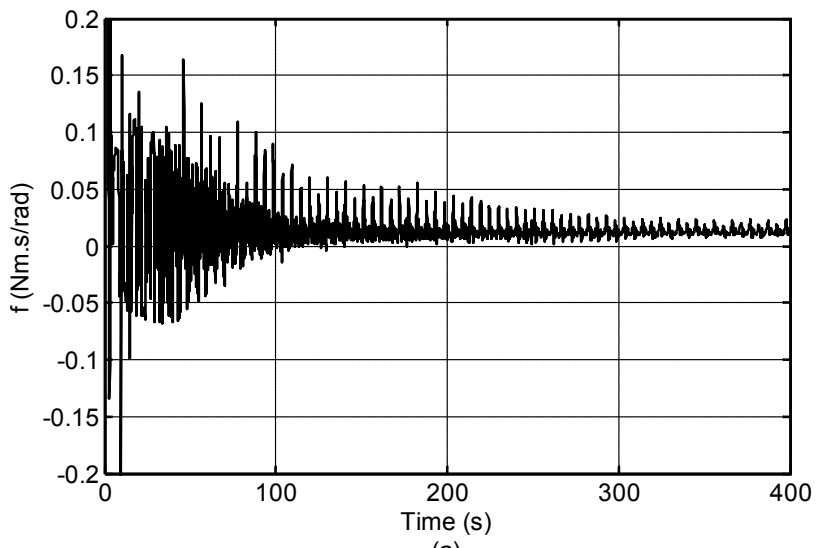

(a)

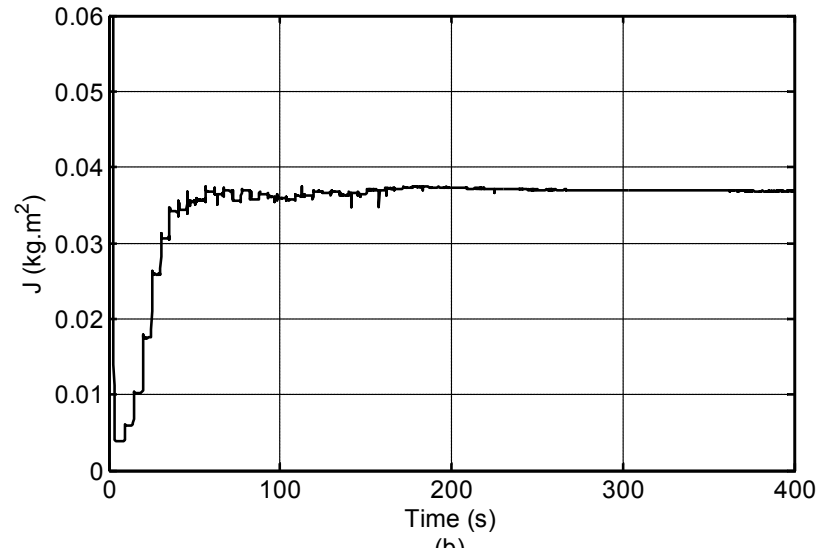

(b)

\subsection{Harmonic speed response based method}

Fig. 10 shows the ADALINE weights evolution and the error between the actual and the estimated speed. In Fig. 10(a), the weights $w_{1}$ and $w_{2}$ are stabilized at 37.2 and -78.1 respectively. The error, as shown in Fig. 10(b), still relatively significant compared to that obtained using the first method. This is due to the presence of arctan function in (19) which is very sensitive to the weight variations. In Fig. 11, the convergence of the parameters $J$ and $f$ is shown. In the steady state, the two parameters are: $J=0.0394 \mathrm{~kg} . \mathrm{m}^{2}$ and $f=0.0123$ N.m.s $/ \mathrm{rad}$. As shown in Fig. 11(a), the viscous damping coefficient $f$ seems better identified than in the first method. A significant improvement in precision is obtained. The application of this method consists to filter the speed signal and to extract the fundamental component. It results in a constant value of $J$ and $f$.

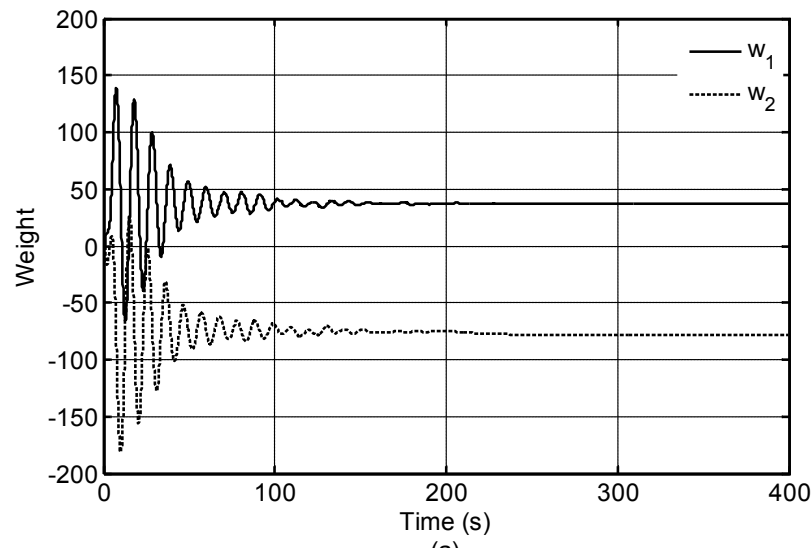

(a)

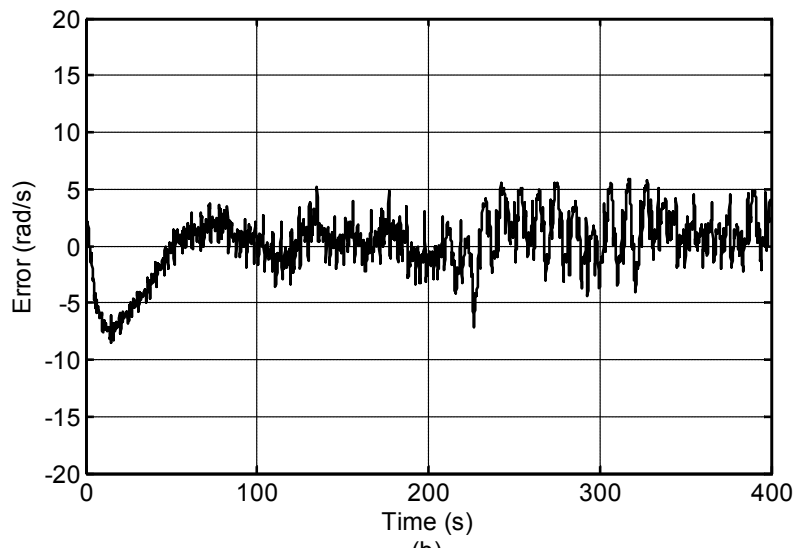

(b)

Fig. 10. Evolution of the weights (a) and the prediction error (b).

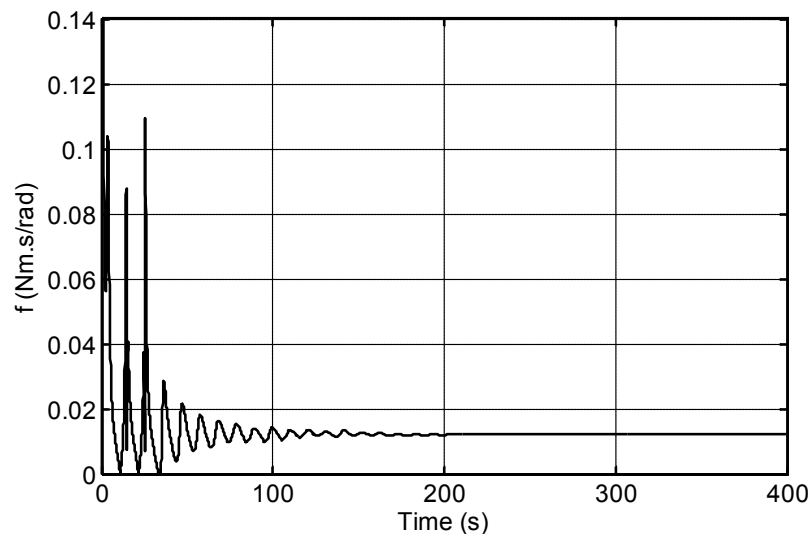

(a)

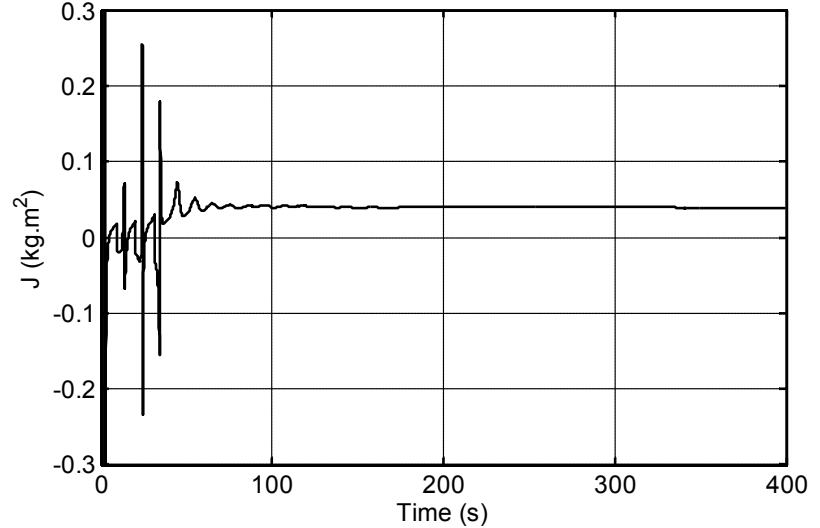

(b)

Fig. 11. Identified parameters: viscous damping coefficient (a) and moment of inertia (b). 


\subsection{Validation tests}

To check the accuracy of the identified parameters related to the two proposed methods; two direct starting tests of the IM are carried out. The mechanical speed and the stator phase current are recorded during the transient and steady state. To avoid current peaks during the starting phase, the IM is fed by a reduced voltage via a voltage-source IGBT inverter. The maximum of the voltage is about $100 \mathrm{~V}$ and the frequency is set to $30 \mathrm{~Hz}$. Two tests are carried out in simulation with the identified parameters and under the same conditions. In order to perform a comparison; the experimental measurements and the computed curves of the identified parameters are superimposed on the same graph. Fig. 12 and Fig. 13 give the validation results of the identified parameters using the two proposed methods. These parameters are summarized in Table 2.

Incontestably, the identified parameters seem to be identified accurate since the theoretical curves coincide perfectly with those obtained by experiment. In both cases, the transient state duration is $0.2 \mathrm{~s}$ and the maximal current reaches $20 \mathrm{~A}$ at the beginning, then, it's equal to $3 \mathrm{~A}$ in the steady state. Nevertheless, a light shift between the simulation and the experiment curves appears at the transient period. It is due to the viscous damping coefficient which constitutes only an average value on the considered speed range.

Table 2

Values of the Identified Parameters

\begin{tabular}{lcc}
\hline & $J\left(\mathrm{~kg} \cdot \mathrm{m}^{2}\right)$ & $f(\mathrm{~N} . \mathrm{m} . \mathrm{s} / \mathrm{rad})$ \\
\cline { 2 - 3 } Mechanical speed equation based method & 0.037 & 0.012 \\
Harmonic speed response based method & 0.039 & 0.0123 \\
\hline
\end{tabular}

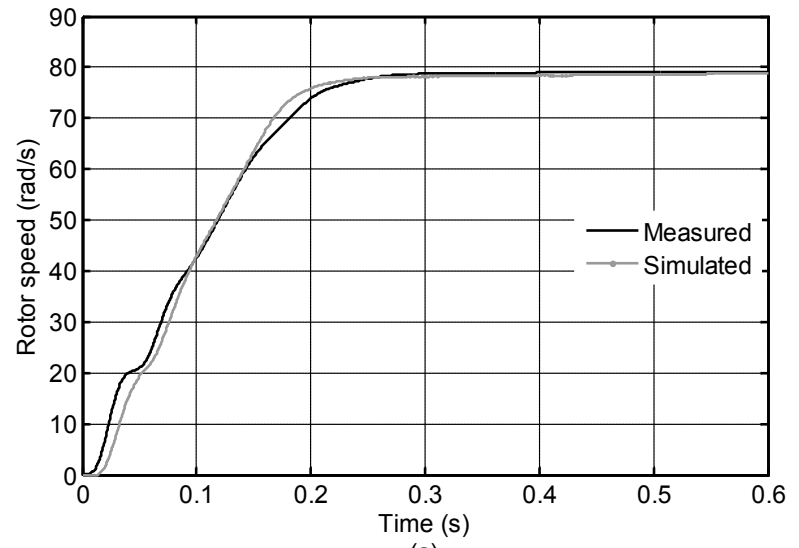

(a)

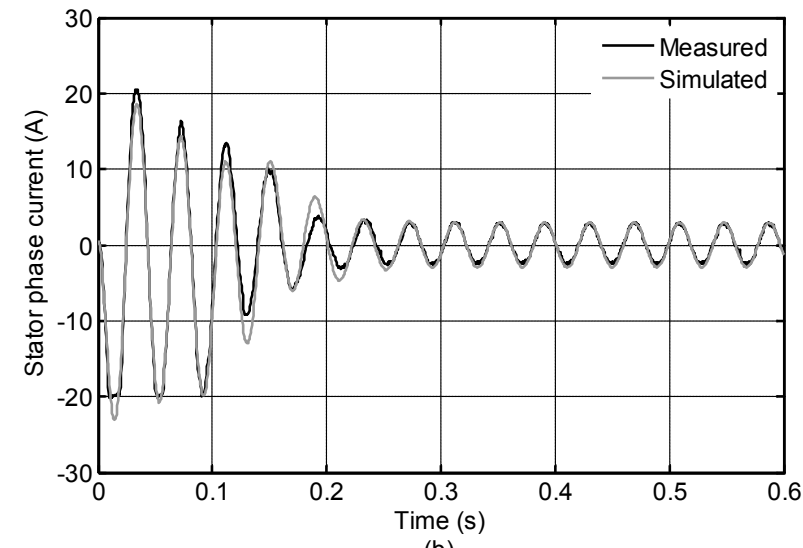

(b)

Fig. 12. Validation test (Mechanical speed equation based method).

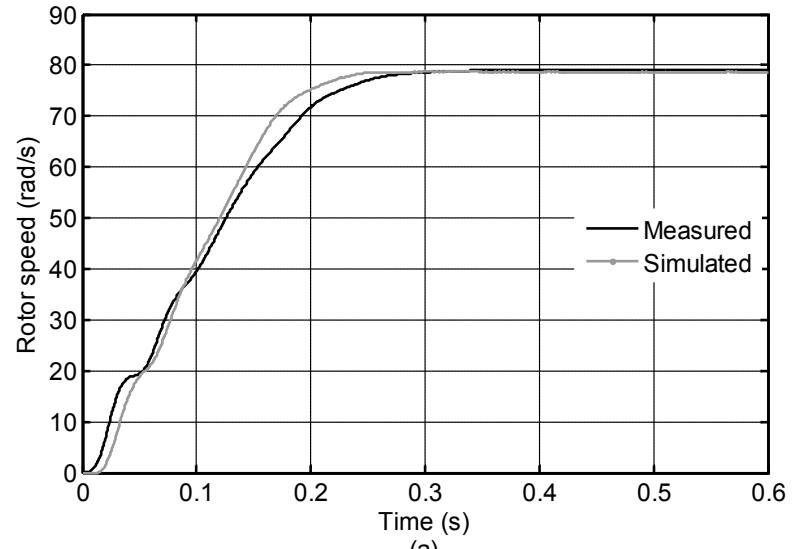

(a)

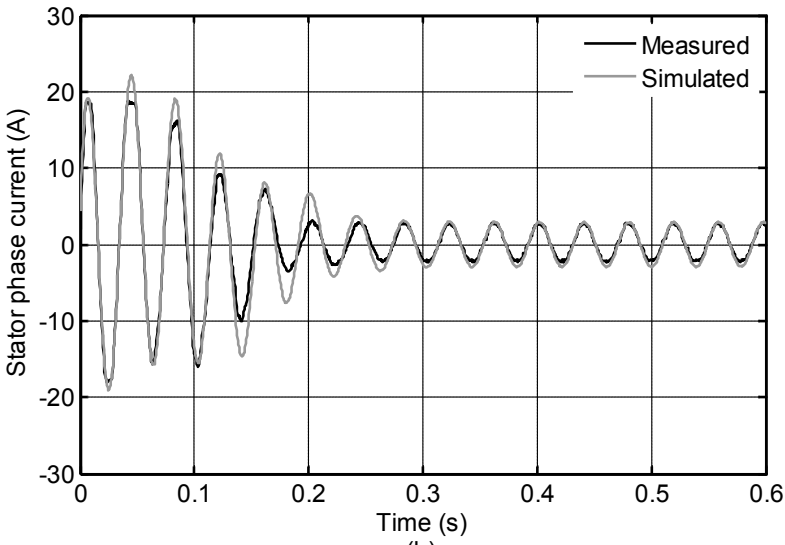

(b)

Fig. 13. Validation test (Harmonic speed response based method) 


\section{Conclusion}

This work demonstrates the effectiveness application of the ADALINE for mechanical parameters identification in vector controlled IM drives. Two online techniques are presented to identify the moment of inertia and the viscous damping coefficient. These methods, based on a single neuron, are very simple to implement. They require the knowledge of the phase currents, the mechanical speed, and a FOC. The first method, more general, exploits recursive form of the mechanical equation. The second one is applied in case of a sinusoidal form of the torque reference. The suggested methods feasibility has been checked by experiments and the identified parameters accuracy has been tested by comparing the experimental results, as well as those obtained from simulations. Nevertheless, for the viscous damping coefficient, and regarding its disparate value, the second method is more accurate. A possible direction for future work, for the purpose of refining the identification, could be the introduction of a coulomb friction into the torque loss.

\section{References}

[1] Q. Ai, Y. Zhou, W. Xu, ADALINE and its application in power quality disturbances detection and frequency tracking, Electric Power Systems Research 77 (5-6) (2007) 462-469.

[2] A. Bechouche, H. Sediki, D. Ould Abdeslam, S. Haddad, A novel method for identifying parameters of induction motors at standstill using ADALINE, IEEE Trans. Energy Convers. 27 (1) (2012) 105-116.

[3] J.-W. Choi, S. C. Lee, H-G. Kim, Inertia identification algorithm for high-performance speed control of electric motors, in: Proceedings of the Electric Power Applications, IEE, vol. 153, no 3, 2006, pp. 379-386.

[4] D. Flieller, D. Ould Abdeslam, P. Wira, and J. Mercklé, Distortions identification and compensation based on artificial neural networks using symmetrical components of the voltages and the currents, Electric Power Systems Research 79 (7) (2009) 11451154.

[5] A. Geodtel, I. N. da Silva, P. J. A. Serni, Load torque identification in induction motor using neural networks techniques, Electric Power Systems Research 77 (2007) 35-45.

[6] M. Jannati, B. Vahidi, S.H. Hosseinian, S.M. Ahadi, A novel approach to adaptive single phase auto-reclosing scheme for EHV transmission lines, Electrical Power and Energy Systems 33 (2011) 639-646.

[7] B. Karanayil, M. F. Rahman, C. Grantham, Online stator and rotor resistance estimation scheme using artificial neural networks for vector controlled speed sensor-less induction motor drive, IEEE Trans. Ind. Electron. 54 (1) (2007) 167-176.

[8] L. Kruger, D. Naunin, C. Garbrecht, Stochastic and neural models of an induction motor, Mathematics and Computers in Simulation 46 (1998) 313-324.

[9] E. Laroche, E. Sedda, E. Durieu, Methodological insights for online estimation of induction motor parameters, IEEE Trans. Contr. Syst. Technol. 16 (5) (2008) 1021-1028.

[10] K. B. Lee, J. Y. Yoo, J. H. Song, I. Choy, Improvement of low speed operation of electric machine with an inertia identification using ROELO, in: Proceedings of the Electric Power Applications, IEE, vol. 151, no 1, 2004, pp. 116-120.

[11] Y. Oguz, M. Dede, Speed estimation of vector controlled squirrel cage asynchronous motor with artificial neural networks, Energy Conversion and Management 52 (2011) 675-686.

[12]D. Ould Abdeslam, P. Wira, J. Mercklé, D. Flieller, Y.-A. Chapuis, A unified artificial neural network architecture for active power filters, IEEE Trans. Ind. Electron. 54 (1) (2007) 61-76.

[13]B. Pryymak, J. M. Moreno-Eguilaz, J. Peracaula, Neural network flux optimization using a model of losses in induction motor drives, Mathematics and Computers in Simulation 71 (2006) 290-298.

[14]B. Robyns, H. Buyse, F. Labrique, Fuzzy logic based field orientation in an indirect FOC strategy of an induction actuator, Mathematics and Computers in Simulation 46 (1998) 265-274.

[15]D. Telford, M.W. Dunnigan, B.W. Williams, Online identification of induction machine electrical parameters for vector control loop tuning, IEEE Trans. Ind. Electron. 50 (2) (2003) 253-261.

[16]R.-J. Wai, J.-M. Chang, Intelligent control of induction servo motor drive via wavelet neural network, Electric Power Systems Research 61 (2002) 67-76.

[17]Z. Q. Wang, M. T. Manry, J. L. Schiano, LMS learning algorithms: misconceptions and new results on convergence, IEEE Trans. Neural Networks 11 (1) (2000) 47-56.

[18]B. Widrow, M. Kamenetsky, Statistical efficiency of adaptive algorithms, Neural Networks 16 (2003) $735-744$.

[19]B. Widrow, M. A. Lehr, 30 years of adaptive neural networks: perceptron, madaline, and backpropagation, in: Proceedings of the IEEE, vol. 78, no 9, 1990, pp. 1415-1442.

[20] M. Wlas, Z. Krzeminski, H. A. Toliyat, Neural-network-based parameter estimations of induction motors, IEEE Trans. Ind. Electron. 55 (4) (2008) 1783-1794. 